\title{
Medical Co-Morbidity in Schizophrenia from Rural Region of Central India: A Cross-Sectional Study
}

\author{
Siddharth Kalucha', Sachin Ratan Gedam², Prakash Behere ${ }^{3}$
}

\section{Siddharth Kalucha', Sachin Ratan Gedam², Prakash Behere ${ }^{3}$}

\section{${ }^{1}$ Resident, Department of Psychiatry,} Jawaharlal Nehru Medical College, Sawangi (Meghe), Wardha, Maharashtra, INDIA.

${ }^{2}$ Assistant Professor, Department of Psychiatry, Mahatma Gandhi Institute of Medical Sciences Sevagram, Wardha, Maharashtra, INDIA.

${ }^{3}$ Professor of Psychiatry, Vice Chancellor, D Y Patil Education Society (Deemed University) Kolhapur, Maharashtra, INDIA.

\section{Correspondence}

Dr. Sachin Ratan Gedam, MD

Assistant Professor, Department of Psychiatry, Mahatma Gandhi Institute of Medical Sciences Sevagram, Wardha, Maharashtra, INDIA.

Mobile no: +918983646448; +917152284341

Email: sachinrgedam@gmail.com

\section{History}

- Submission Date: 19-03-2017

- Revised Date: 19-05-2017

- Accepted Date: 10-11-2017

\section{DOI : 10.5530/ijmedph.2017.4.40}

\section{Article Available online}

http://www.ijmedph.org/v7/i4

\section{Copyright}

(C) 2017 Phcog.Net. This is an openaccess article distributed under the terms of the Creative Commons Attribution 4.0 International license.

\begin{abstract}
Background: The patients with schizophrenia have higher mortality rates and shortened life span. The major causes of this excess mortality are medical disease, unhealthy lifestyle, substance misuse, poor compliance or treatment refusal, and suicide among unnatural causes. The peoples diagnosed with schizophrenia expect to live 9-12 years lesser than those in the general population on average. Objectives: To study the prevalence of medical co-morbidities; association of medical co-morbidities with socio-demographic and clinical variables among schizophrenia patients; and to determine the association of I.C.D. -10 subtypes of schizophrenia with medical co-morbidities. Materials and methods: The cross-sectional study was conducted on 100 patients over a period of 4 months as per defined inclusion and exclusion criteria at tertiary care center. A semi-structured proforma, designed for the study was used to collect the sociodemographic and clinical details. Results: Co-morbid medical illness was reported in $22 \%$ of patients. The most common physical illness was endocrinological disorders (31.82\%). The patients who had higher age and exposure to psychotropic medications were significantly associated with medical co-morbidities $(p<0.05)$. The co morbid medical illnesses were not significantly associated with type of medication used, subtype of schizophrenia and family history of mental illness ( $p>0.05$ ) whereas reported significant association with history of substance use $(p<0.05)$. Conclusion: The prevalence of medical co-morbidities was found to be $22 \%$, lower than that in previous literature. Sometimes the physical illnesses remain unrecognized in such patients so integrated approaches require for prevention and treatment modalities.
\end{abstract}

Key words: Medical illness, Co-morbidities, Schizophrenia, Chronic illness.

\section{INTRODUCTION}

The patients with schizophrenia have higher mortality rates and shortened life span as compared to the general population. ${ }^{1,2}$ The literature reported that the major causes of this excess mortality are medical disease, unhealthy lifestyle, substance misuse, poor compliance or treatment refusal, and suicide among unnatural causes. ${ }^{3}$

This vulnerable group of patients does not receive the physical health care because of physical symptoms being misinterpreted as part of physical illness by professionals, lack of motivation, social isolation, poor social skills and cognitive impairment making them less likely to adhere to treatment. ${ }^{4}$ The peoples diagnosed with schizophrenia can expect to live 9-12 years fewer than those in the general population on average. ${ }^{5}$ Recent literature showed that men with schizophrenia die 20 years earlier and women die 15 years earlier than people without major mental illness. ${ }^{6}$ The common physical conditions found in patients with mental illness include diabetes, hyperlipidaemia, cardiovascular disease (hypertension, cardiac arrhythmias), obesity, malignant neoplasm, HIV/ AIDS, Hepatitis C, osteoporosis, hyperprolactinaemia and other physical illnesses. ${ }^{7}$ A study by Sokal et al reported greater odds of respiratory illnesses for persons with schizophrenia even after controlling for smoking and medical illnesses found to be more severe among them. ${ }^{8,9}$

Mortensen and Juel noted that some proportion of mortality in schizophrenia may be directly associated with side effects of neuroleptic medications. ${ }^{10}$ Several factors are known to increase the risk of medical disorders among mental illness. Among them are use of medications that contribute to weight gain, which is associated with diabetes and hypertension; poor attention to personal hygiene, which is associated with skin infections; high rates of smoking, which contributes to asthma, acute respiratory disease, heart disease, and lung cancer; reduced physical activity and fitness, which contributes to hypertension and heart disease; and use of medications with adverse gastrointestinal effects. ${ }^{9}$

Some variances associated with mental illness may remain unexplained. In our country, the study has not received much attention. Hence this study was undertaken to know the present scenario in the rural region.
Cite this article : Kalucha S, Gedam SR, Behere P. Medical Co-Morbidity in Schizophrenia from Rural Region of Central India: A Cross-Sectional Study. Int J Med Public Health. 2017;7(4):191-5. 
The aims and objectives of the present study are as follows:

1. To determine the prevalence of medical co-morbidities in schizophrenia patients.

2. To study the association of medical co-morbidities with sociodemographic and clinical variables.

3. To determine the association of I.C.D. - 10 subtypes of schizophrenia with medical co-morbidities.

\section{MATERIAL AND METHOD}

\section{Study design and sample}

The cross-sectional study was conducted at Department of Psychiatry, Jawaharlal Nehru Medical College, Sawangi (M) Wardha, Maharashtra, India. The approval from Institutional ethics committee was obtained prior to the study. Total 100 patients diagnosed as schizophrenia as per International Classification of Diseases $-10^{\text {th }}$ revision of WHO (ICD-10) diagnostic criteria fulfilling the inclusion and exclusion criteria between Jan to Apr 2013 were included in the study. The majority of the physical illnesses were diagnosed by medical specialists within our hospital setup and documented in the medical records of the patients.

\section{Inclusion criteria}

1. Patients in the age group of more than 18 and less than 55 years of age (due to increase risk of cognitive deficits in the patients).

2. Patients diagnosed to be suffering from Schizophrenia according to ICD 10 criteria.

3. Patients who were stable on medications since at least past three months.

4. Both inpatients and out patients.

\section{Exclusion criteria}

1. Patients who were violent and uncooperative.

2. Patients who have any cognitive deficits and mentally subnormal patients.

3. Patients with any other psychiatric co-morbidity.

4. Patients not accompanied with reliable relative, previous medical record or documents.

\section{Tools}

A semi-structured proforma, designed for the study was used to collect the socio-demographic and clinical details. ICD-10 diagnostic criteria were used to validate the diagnosis of schizophrenia.

\section{Procedure}

The patient and close relative were explained the nature of the study. The written consent obtained from the patient. The patient was then interviewed using the available tools. The relative was subsequently interviewed to obtain other relevant details along with previous medical records or documents. Whenever patient presented with any physical complaint he/she was referred to consultant physician at our Institute. The diagnosis and treatment given by physician was entered into the record. Those patients who were already having co-morbid physical illness were entered in proforma. Thus presences of medical co morbidities were assessed using family member report, patient self-report or previous medical records.

\section{Statistical analysis}

The data was collected and entries were done using SPSS version 17.0 and Epi Info software. Analysis was studied using Chi square test and Odds ratio. $P$ value of less than 0.05 was considered statistically significant.

\section{RESULTS}

The sample consisted of 47 male and 53 female schizophrenia patients (Table 1). The mean age of onset of schizophrenia was 29.24 years (SD 13.07), mean duration of illness was 8.40 years (SD 8.60) and 93\% patients had less than 20 years of duration of schizophrenia (Table 2). The result reported, $69 \%$ patients were exposed to psychotropic medications for less than 5 years while 23\% were exposed for 6 to 10 years; $22.73 \%$ of patients had medical illness before onset of schizophrenia and $77.27 \%$ had developed medical illness after the onset of schizophrenia (Table 2). Among them medical illness worsened schizophrenia in $27.27 \%$ of patients (Table 2) and causes may include electrolyte disturbances such as hypocalcaemia, hyponatremia, hypernatremia, hypokalemia, hypomagnesemia; disorders causing the delirious state and endocrine disorders causing hormonal changes. It was found that schizophrenia patients who had higher age and exposure to psychotropic medications were significantly associated with medical co-morbidities (Table 3 ). The patients with schizophrenia developing medical illness were not significantly associated with duration of illness (Table 3). The co morbid medical illnesses were not associated with type of medication used, subtype of schizophrenia and family history of mental illness whereas reported significant association with history of substance use (Table 4).

As shown in Figure 1, prevalence of medical co morbidities found to be $22 \%$. The endocrine disorders were found to be highest $(32 \%)$ followed by disorders of respiratory system (Figure 2). Figure 3 showed, 67\% were exposed to atypical anti psychotics, $11 \%$ were exposed to typical anti psychotics while $22 \%$ were exposed to combination of both typical and atypical anti psychotic. Out of total patients, $78 \%$ were diagnosed as suffering from paranoid schizophrenia, $12 \%$ from undifferentiated schizophrenia, 3\% from hebephrenic schizophrenia, $2 \%$ from catatonic schizophrenia and 5\% from other types (Figure 4).

\section{DISCUSSION}

Schizophrenia has been described as a "life-shortening disease". People with schizophrenia and other mental illnesses have high rates of preventable risk factors and physical co morbidity accounts for $60 \%$ of premature deaths. ${ }^{11}$ Koran et al estimated that $45 \%$ of patients in California's public mental-health system had physical disease. ${ }^{12}$ A study by Koranyi et al of psychiatric clinic patients revealed that $43 \%$ of patients had physical illnesses. ${ }^{13}$ Hall et al found that $46 \%$ of patients admitted had an unrecognized physical illness that either caused or exacerbated their psychiatric illness. ${ }^{14}$ In our study we found $22 \%$ of medical co morbidity in schizophrenia patients. It is lower than that found in other studies. This disparity may be due to the fact that the present study setting was in rural area and low socio-economic strata, many people were not affording thorough medical investigations; bringing the percentage of medical co morbidity to lower levels.

A study by Holt and Pevler reported that diabetes occurred in 15\% patients with schizophrenia lower as compared to present study. ${ }^{15}$

\begin{tabular}{|cccc|}
\multicolumn{4}{l}{ Table 1: Age and Gender wise distribution of the patients } \\
Age (years) & Male (\%) & Female (\%) & Total (\%) \\
$<20$ & $4(4 \%)$ & $3(3 \%)$ & $7(7 \%)$ \\
$21-40$ & $30(30 \%)$ & $33(33 \%)$ & $63(63 \%)$ \\
$41-60$ & $11(11 \%)$ & $15(15 \%)$ & $26(26 \%)$ \\
$61-80$ & $2(2 \%)$ & $2(2 \%)$ & $4(4 \%)$ \\
Total & $47(47 \%)$ & $53(53 \%)$ & $100(100 \%)$ \\
Mean & 37.97 & 36.96 & 37.44 \\
SD & 11.22 & 12.08 & 11.64 \\
\hline
\end{tabular}




\begin{tabular}{|c|c|c|c|}
\hline Age of onset & No of patients & Percentage (\%) & Mean \pm SD \\
\hline$<20$ & 26 & 26 & $29.24 \pm 13.07$ \\
\hline $21-40$ & 58 & 58 & \\
\hline $41-60$ & 15 & 15 & \\
\hline $61-80$ & 1 & 1 & \\
\hline Duration of illness(yrs.) & No of patients & Percentage (\%) & \\
\hline$<20$ & 93 & 93 & $8.40 \pm 8.60$ \\
\hline $21-40$ & 7 & 7 & \\
\hline $\begin{array}{c}\text { Exposure to } \\
\text { psychotropic medication }\end{array}$ & No of patients & Percentage (\%) & \\
\hline$<5$ years & 69 & 69 & $4.68 \pm 4.34$ \\
\hline $6-10$ years & 23 & 23 & \\
\hline $11-15$ years & 5 & 5 & \\
\hline $20-25$ years & 3 & 3 & \\
\hline Distribution of medical illness & No of patients & Percentage (\%) & \\
\hline Before & 5 & 22.73 & \\
\hline After & 17 & 77.27 & \\
\hline $\begin{array}{c}\text { Effect of medical illness on } \\
\text { schizophrenia }\end{array}$ & No of patients & Percentage (\%) & \\
\hline Worsen & 6 & 27.27 & \\
\hline Does not worsen & 16 & 72.73 & \\
\hline
\end{tabular}

\begin{tabular}{|c|c|c|c|c|c|c|}
\hline Medical IIIness & $\mathrm{n}$ & $\begin{array}{l}\text { Mean } \\
\text { Age }\end{array}$ & Std. Deviation & $\begin{array}{l}\text { Std. Error } \\
\text { Mean }\end{array}$ & $z$-value & $p$-value \\
\hline Yes & 22 & 43.59 & 10.21 & 2.17 & \multirow{2}{*}{2.90} & \multirow{2}{*}{0.004} \\
\hline No & 78 & 35.70 & 11.49 & 1.30 & & \\
\hline Medical Illness & $\mathrm{n}$ & $\begin{array}{c}\text { Duration of mental } \\
\text { illness }\end{array}$ & Std. Deviation & $\begin{array}{l}\text { Std. Error } \\
\text { Mean }\end{array}$ & $z$-value & $\mathrm{p}$-value \\
\hline Yes & 22 & 11.27 & 8.55 & 1.82 & \multirow{2}{*}{1.79} & \\
\hline No & 78 & 7.58 & 8.49 & 0.96 & & 0.076 \\
\hline Medical Illness & $\mathrm{n}$ & $\begin{array}{l}\text { Exposure to } \\
\text { psychotropic } \\
\text { medication }\end{array}$ & Std. Deviation & $\begin{array}{l}\text { Std. Error } \\
\text { Mean }\end{array}$ & $\mathrm{z}$-value & $\mathrm{p}$-value \\
\hline Yes & 22 & 6.58 & 6.05 & 1.29 & \multirow{2}{*}{2.60} & \multirow[b]{2}{*}{0.011} \\
\hline No & 78 & 3.85 & 3.72 & 0.42 & & \\
\hline
\end{tabular}

Increased risk in people with schizophrenia of developing glucoseregulation abnormalities, insulin resistance and type 2 diabetes mellitus found to be due to lifestyle factors (poor diet, sedentary behaviour); and all antipsychotic agents (atypical more than typical) increase the propensity to develop diabetes. ${ }^{16,17,18}$ People with severe mental illness have 2-3 times more risk for cardiovascular disorders than the general population. People with mental illness have higher rates of cardiovascular and respiratory disorders than the general population; antipsychotic agents contribute to metabolic syndrome X (hypertension, hyperlipidaemia, hyperglycaemia, insulin resistance and obesity); lifestyle factors (smoking, alcoholism, poor diet, and lack of exercise) contribute to increased risk of cardiac problems. Mortality due to ischaemic heart disease, cardiac arrhythmias and myocardial infarction is higher in people with mental illness. ${ }^{19,20,21,22}$ The present study reported prevalence of endocrinal abnormalities to be higher (31.82\% especially diabetes mellitus type -2$)$ than the cardiovascular morbidity at $9.09 \%$ and the patients who had higher age were associated with increased risk of physical illness. Our findings are consistent with a study conducted by Smith DJ et al who reported that people with schizophrenia had lower recorded rates of cardiovascular disease as compared to other physical health co morbidities. ${ }^{23}$ The variation as compared to other studies can be accounted to the fact of difference in sample demographics like variations in setting, as our study was on rural population.

It is a well-known fact that both typical and atypical antipsychotics though are main stay of treatment for schizophrenia, are also associated with their side effects. Gupta et al (2003) reported a prevalence rate of $30 \%$ for hypertension, $17 \%$ for diabetes and $43 \%$ for lipid abnormalities in 208 patients with psychotic disorders who were receiving anti-psychotic medications. ${ }^{24}$ Risk of metabolic syndrome also found to be higher in patients being treated with atypical antipsychotics. Heiskanen et al (2003) 


\begin{tabular}{|c|c|c|c|c|c|}
\hline & & $\begin{array}{l}\text { I Illness } \\
\text { No }\end{array}$ & Total & $\aleph 2$-value & p-value \\
\hline \multicolumn{6}{|l|}{ Type of medication } \\
\hline Atypical & 14 & 53 & 67 & 0.49 & \multirow{3}{*}{0.78 ,NS } \\
\hline Typical & 2 & 9 & 11 & & \\
\hline Mixed & 6 & 16 & 22 & & \\
\hline \multicolumn{6}{|c|}{ ICD 10 classification of schizophrenia } \\
\hline Paranoid & 17 & 61 & 78 & 0.86 & \multirow{5}{*}{0.93} \\
\hline Undifferentiated & 3 & 9 & 12 & & \\
\hline Catatonic & 0 & 2 & 2 & & \\
\hline Hebephrenic & 1 & 2 & 3 & & \\
\hline Other & 1 & 4 & 5 & & \\
\hline \multicolumn{6}{|l|}{ H/O Substance Abuse } \\
\hline Yes & 7 & 11 & 18 & 3.87 & \multirow[b]{2}{*}{0.046} \\
\hline No & 15 & 67 & 82 & & \\
\hline \multicolumn{6}{|c|}{ Family H/O mental illness } \\
\hline Yes & 5 & 25 & 30 & 0.71 & \multirow[b]{2}{*}{0.39} \\
\hline No & 17 & 53 & 70 & & \\
\hline
\end{tabular}
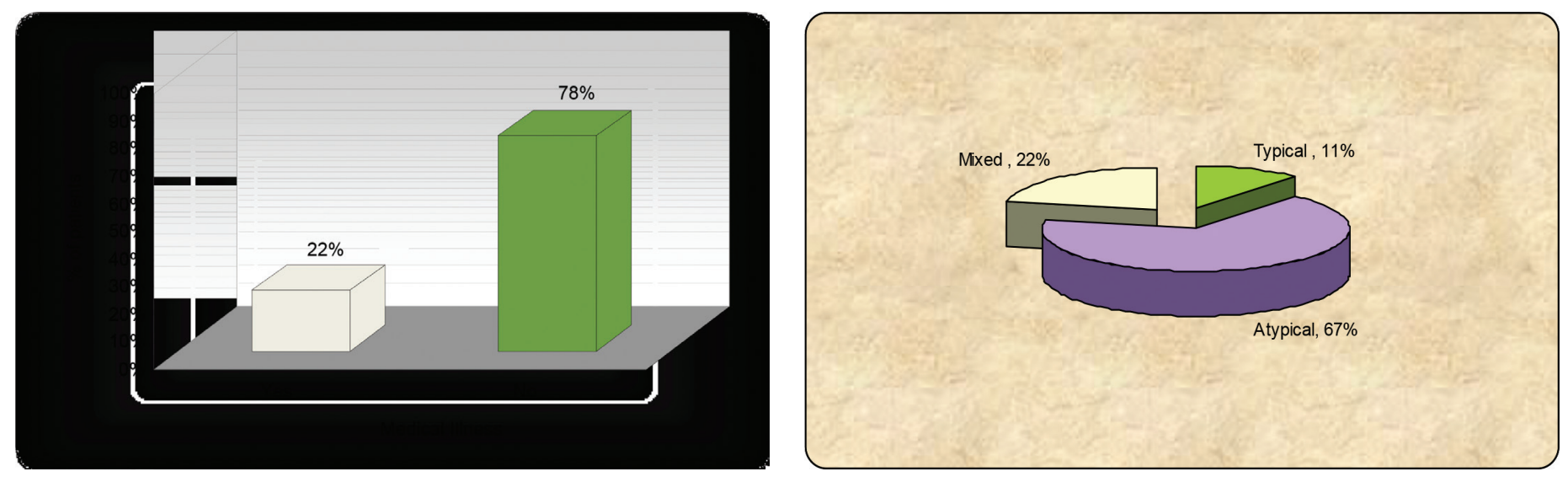

Figure 1: Distribution according to presence of medical illness.

Figure 3: Distribution according to type of medication.
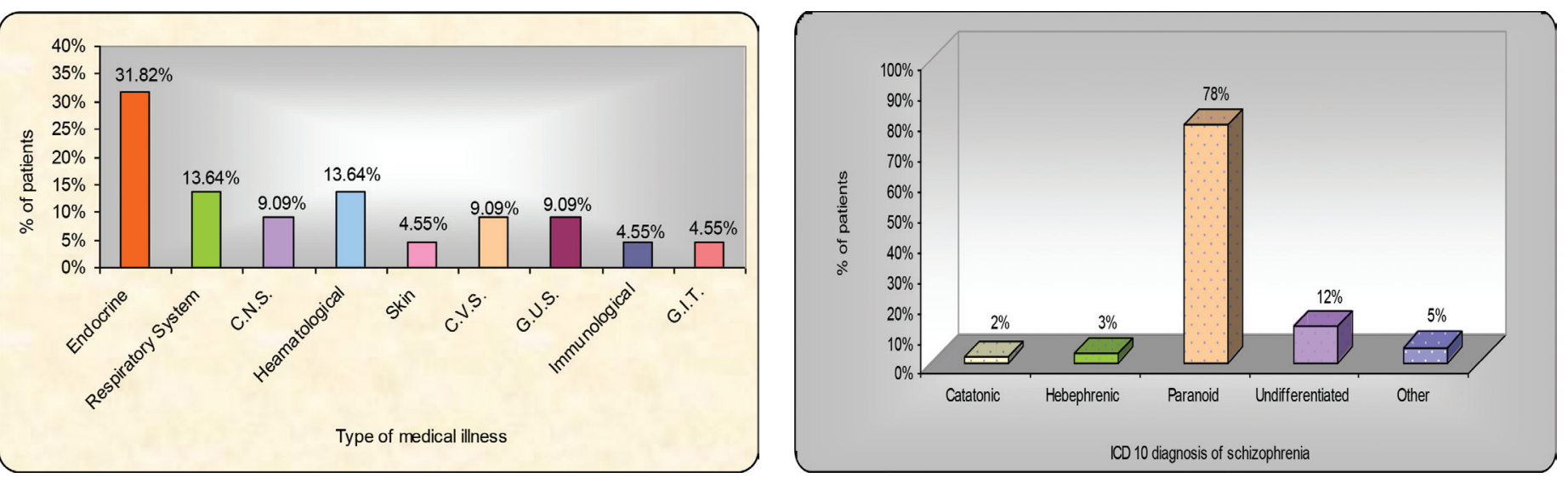

Figure 2: Distribution of mental illness according to medical co morbidities.

Figure 4: Distribution according to I.C.D. 10 diagnosis of schizophrenia. 
found that $37 \%$ of patients with schizophrenia receiving antipsychotic medications developed metabolic syndrome higher as compared to present study. ${ }^{25}$ Tarricone et al (2006) found that patients treated with atypical antipsychotics had higher mean glycaemia and triglyceridemia and a significantly higher risk of receiving a diagnosis of hyperglycemia and hypertriglyceridemia than the reference group. ${ }^{26}$ The above findings are consistent with the results reported in present study that patients who were exposed to psychotropic medications for longer periods of time, were more at risk of developing medical illness (majority of our patients i.e. $67 \%$ were being treated with atypical antipsychotics).

High alcohol use in schizophrenia is associated with more severe psychiatric symptoms and more disturbed behavior. ${ }^{27}$ Poor medication compliance, higher rates of re hospitalization and poor treatment response has been associated with comorbid drug abuse in schizophrenia. ${ }^{28,29}$ Smoking rates is found to be higher in schizophrenia subjects than in normal population..$^{30}$ The present study also found that history of substance abuse in schizophrenia increased the risk of developing medical co-morbidities. This finding is in accordance with above mentioned studies.

Literature is limited for medical co-morbidity seen in different subtypes of schizophrenia as described in ICD-10. This study also did not find any difference in subtypes of schizophrenia and prevalence of medical co-morbidity. Similarly literature is very limited on prevalence of medical comorbidity in schizophrenia and its correlation with family history of mental illness. The present study found that having a family history of mental illness in patients with schizophrenia does not increase the likelihood of development of physical Illness.

\section{CONCLUSION}

The prevalence of medical co-morbidities was found to be lower than that in previous literature. As shown by this study schizophrenia patients reported co-morbid diabetes mellitus, C.O.P.D, hypertension, anaemia among many others. More the exposure to psychotropic mediations in term of duration increased the chances of developing medical illness. Sometimes the physical illnesses remain unrecognized in such patients so integrated approaches such as assessment of medical illness by physician and psychiatric diagnosis by psychiatrist require to prevent and treat the co-morbid disorders. Further research is needed to provide more insight into the risk factors and treatment modalities.

\section{CONFLICT OF INTEREST}

The authors declare no conflict of interest.

\section{ABBREVIATION USED}

ICD: International Classification of Diseases; HIV: Human immunodeficiency virus; AIDS: Acquired immune deficiency syndrome; SPSS: Statistical Package for the Social Sciences; COPD: Chronic Obstructive Pulmonary Disease.

\section{REFERENCES}

1. Saha $S$, Chant $D$, mcgrath J. A systematic review of mortality in schizophrenia: Is the differential mortality gap worsening over time?. Arch Gen Psychiatry. 2007; 64(10):1123-31.

2. Capasso RM, Lineberry TW, Bostwick JM, Decker PA, St Sauver J. Mortality in schizophrenia and schizoaffective disorder: An Olmsted County, Minnesota cohort: 1950-2005. Schizophr Res. 2008;98(1):287-94.

3. Brown S, Inskip H, Barraclough B. Causes of the excess mortality of schizophrenia.
Br J Psychiatry. 2000;177(3):212-7.

4. Phelan M, Stradins L, Morrison S. Physical health of people with severe mental illness. BMJ. 2001;322(7284):443-4.

5. Ruschena D, Mullen PE, Burgess $P$, et al. Sudden death in psychiatric patients. Br J Psychiatry. 1998;172:331-6

6. Tiihonen J, Lönnqvist J, Wahlbeck $K$, et al. 11-year follow-up of mortality in patients with schizophrenia: a population-based cohort study (FIN11 study). Lancet. 2009;374:620-27.

7. Timothy JRL, Dennis $V$, Christos P. Medical comorbidity in schizophrenia. SUPPLEMENT SCHIZOPHRENIA; MJA. 2003;178:S67-S70.

8. Sokal J, Messias E, Dickerson FB, et al. Comorbidity of medical illnesses among adults with serious mental illness who are receiving community psychiatric services. J Nerv Ment Dis. 2004;192(6):421-7.

9. Dixon L, Postrado L, Delahanty J, Fischer PJ, Lehman A. The association of medical comorbidity in schizophrenia with poor physical and mental health. $J$ Nerv Ment Dis. 1999;187(8):496-502.

10. Mortensen PB, Juel K. Mortality and causes of death in first admitted schizophrenic patients. British Journal of Psychiatry. 1993;163(2):183-9.

11. Lambert TJ, Velakoulis D, Pantelis C. Medical comorbidity in schizophrenia. Med J Aust. 2003;178 Suppl:S67-70.

12. Koran LM, Sox HC, Marton KI, et al. Medical evaluation of psychiatric patients. I. Results in a state mental health system. Arch Gen Psychiatry. 1989;46(8):733-40

13. Koranyi EK. Morbidity and rate of undiagnosed physical illnesses in a psychiatric clinic population. Arch Gen Psychiatry. 1979;36(4):414-9.

14. Hall RC, Gardner ER, Popkin MK, et al. Unrecognized physical illness prompting psychiatric admission: a prospective study. Am J Psychiatry. 1981;138(5):629-35.

15. Holt RIG, Peveler RC. Association between antipsychotic drugs and diabetes. Diabetes Obesity and Metabolism. 2006;8(2):125-35.

16. Dixon L, Weiden P, Delahanty J, et al. Prevalence and correlates of diabetes in national schizophrenia samples. Schizophr Bull. 2000;26(4):903-12.

17. Sernyak M, Leslie $D$, Alarcon $R$, et al. Association of diabetes mellitus with use of atypical neuroleptics in the treatment of schizophrenia. Am J Psychiatry. 2002;159(4):561-6.

18. Felker B, Yazel JJ, Short D. Mortality and medical comorbidity among psychiatric patients: a review. Psychiatr Serv. 1996;47:1356-63.

19. Lawrence D, Holman C, Jablensky A. Preventable physical illness in people with mental illness. Perth: University of Western Australia, 2001. Available at: http:// www.meddent.uwa.edu.au/dph_new/research/docs/trctotal.pdf (accessed Mar 2003)

20. Davidson M. Risk of cardiovascular disease and sudden death in schizophrenia. J Clin Psychiatry. 2002;63:5-11. (Erratum appears in J Clin Psychiatry. 2002; 63:744.)

21. Ryan MC, Thakore JH. Physical consequences of schizophrenia and its treatment: the metabolic syndrome. Life Sci. 2002;71:239-57.

22. Kendrick T. Cardiovascular and respiratory risk factors and symptoms among general practice patients with long-term mental illness. $\mathrm{Br} J$ Psychiatry. 1996;169(6):733-9.

23. Smith DJ, Langan J, mclean G, et al. Schizophrenia is associated with excess multiple physical-health comorbidities but low levels of recorded cardiovascular disease in primary care: cross-sectional study. BMJ Open. 2013:3(4):e002808. Doi:10.1136/ bmjopen-2013-002808.

24. Gupta S, Steinmeyer C, Frank B, Madhusoodanan S, Lockwood K, Lentz B, et al. Hyperglycemia and hypertriglyceridemia in real world patients on antipsychotic therapy. Am J Ther. 2003;10:348-55.

25. Heiskanen T, Niskanen L, Lyytikäinen R, Saarinen PI, Hintikka J. Metabolic syndrome in patients with schizophrenia. J Clin Psychiatry. 2003;64(5):575-9.

26. Ilaria $T$, Michela $C$, Beatrice FG, Daniela G, Marco M. Alessandro $S$, et al. Metabolic risk factor profile associated with use of second generation antipsychotics: a cross sectional study in a community mental health centre. BMC Psychiatry. 2006;6(1):11.

27. Duke PJ, Pantelis C, Barnes TR. South Westminster schizophrenia survey: Alcohol use and its relationship to symptoms, tardive dyskinesia, and illness onset. British Journal of Psychiatry. 1994;164(5):630-6.

28. Drake RE, Osher FC, Wallach MA. Alcohol use and abuse in schizophrenia: A prospective community study. Journal of Nervous and Mental Disease. 1989;177(7):408-14.

29. Mueser KT, Bellack AS, Blanchard JJ. Comorbidity of schizophrenia and substance abuse: Implications for treatment. Journal of Consulting and Clinical Psychology. 1992;60(6):845-56.

30. Hughes JR, Hatsukami DK, Mitchell JE, Dahlgren LA. Prevalence of smoking among psychiatric outpatients. American Journal of Psychiatry. 1986;143(8):993-7. 